\title{
Equipment Performance Due to Voltage Sags - Test Results for Contactor and Induction Motor
}

\author{
Surya Hardi, Muhd. Hafizi, Muzamir Isa, Rohana Ismail
}

\begin{abstract}
This paper presents experimental test results of contactor and induction motor performances when they were supplied by voltage sags. A Programmable source is used to generate various voltage sag characteristics. A small of contactor and induction motor were used for this purpose. Test results show that magnitude and duration are very important aspects that determine performance of the equipments. Influence of other characteristics such as point on wave and repetitive of voltage sag are discussed. Difference of point on wave of sag initiation will cause contactor performance is different for tripping. The occurrence of the second sag after the first one may affect the contactor performance. The contactor performance becomes sensitive when it is supplied by repetitive voltage sags. Voltage sag cause transient current drawn by the motor is too high and it occurs at recovery voltage instant and the value depending on magnitude of the sags. The current peak is not significant influenced by sag duration. The current peak in the second sag is similar to first sag. Therefore presence repetitive of voltage sags on induction motor is not influence on the current peaks.
\end{abstract}

Index Terms-Voltage sags, Testing, Contactor, Induction motor.

\section{INTRODUCTION}

$\mathrm{C}$ ONTACTOR and induction motor are many found in industrial application. Both this equipments are sensitive to voltage sags. Generally the industrial using the contactors are to control of electric motors. Some problems faced by the industrial are voltage sags which is most frequent occurs among various types of power quality disturbance in the utility electrical supply. When the voltage sags occur in the terminal supply of the industrial, it can cause degradation performance of the equipments, such as speed of induction motor will decrease, high current peaks and torque peaks produced at the beginning and the end of voltage sags instans and even for the contactor towards trip. These conditions are very depending on the characteristics of voltage sags.

S. Hardi, M. Hafizi and M. Isa are with the School of Electrical System Engineering, University of Malaysia Perlis (UniMAP), Malaysia.

(e-mail: surya@ unimap.edu.my; hafiziidris@ unimap.edu.my; muzamir@ unimap.edu.my).

R. Ismail is with the Electrical Engineering Department, University of Muhamadyah Sumatera Utara, Indonesia. (e-mail:rohana0511@yahoo.com).
From previous papers show that an ac contactor is electromechanical devices which act as a switch to connect and disconect a variety of electrical system for both power and control purpose that have been identified as sensitive to voltage sags. Results of contactors testing have been documented that the contactors can tolerate any voltage sags drop to about $70 \%$ of nominal voltage. When the sag magnitude is below $70 \%$ for longer than few cycles, the contactor drops out [1]. A study has reported that AC contactors installed an industrial plant in Venezuelan trips after 90 milliseconds (ms) when voltage drops below $60 \%$ of its nominal value [2]. These different performances are due to different a design structure of contactors. During the contactor drop out or trip there is no energy fed by utility supply to industrial and cause production stops, finally causes loss financial.

High current peaks in induction motor can occur when the terminal is supplied by voltage sags. The transient current occurs at drop point and recovery voltage instans. The current peaks at recovery voltage are always higher than drop point. The high current may triger overcurrent protection to trip and then the motors become stall, thus causing a stop in production. The effect of system recovery voltage caused by severe voltage sag and interruption can stress the motor protection such as fuse. Specific energy value that is defined by $\mathrm{I}^{2} \mathrm{t}$ cause the fuse aging and over heating in motor winding [ $3]$. The effect resulted by voltage sags on the induction motor performance depends on some characteristics of the voltage sags.

Voltage sags are mostly caused by short circuit faults on transmission and or distribution lines in power systems. The faults are mainly result from lightning stroke, insulators polluted, animal contact and accidents involving construction or transportation activities. The high fault currents will propagate to entire the circuit that connected together and result in large drops voltage in the circuit. It can also be caused by energizing of heavy loads or starting of large motors. Even though sag durations are generally longer, but voltage drops are small and do not cause serious problems at the industrial customer [1].

Voltage sags are defined as a sudden reduction of the supply the RMS voltage between (10-90) \% of the nominal voltage at the power frequency, for duration from a half cycles to one 
minute. Interruption occurs when the RMS voltage less than $10 \%$ of nominal voltage. If the duration is more than 1 minute it is considered as under voltage [4]. Voltage sag is grouped as instantaneous when its duration with ranges from 0.5 to 30 cycles, momentary lasting between 30 cycles and 3 seconds and temporary extending from 3 to 60 seconds. Point on wave (POW) of sag initiation is the phase angle of the sinusoidal voltage wave at which the voltage sag begins whereas repetitive of voltage sag is sag repeat caused by a fault occurs as the automatic re-closer will open to clear the fault and automatically reclose after a time delay. Both the characteristics are displayed in Fig. 1(a) and (b), respectively.

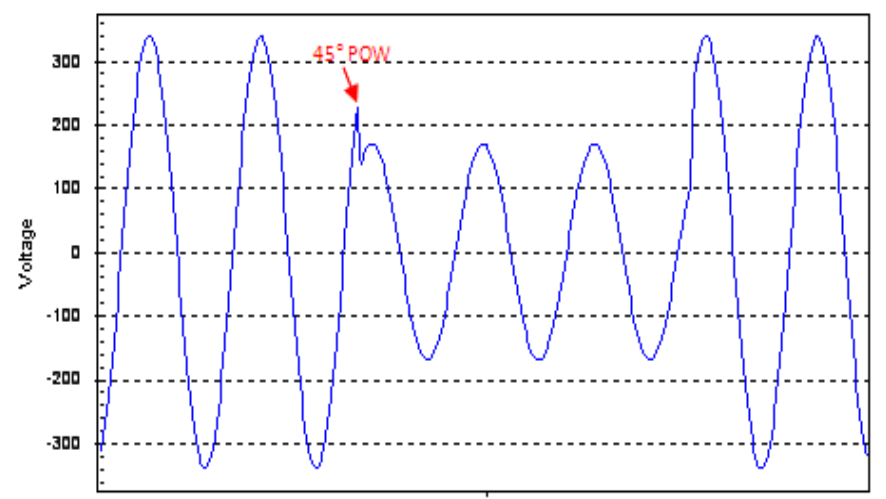

(a) Waveform with POW of sag initiation

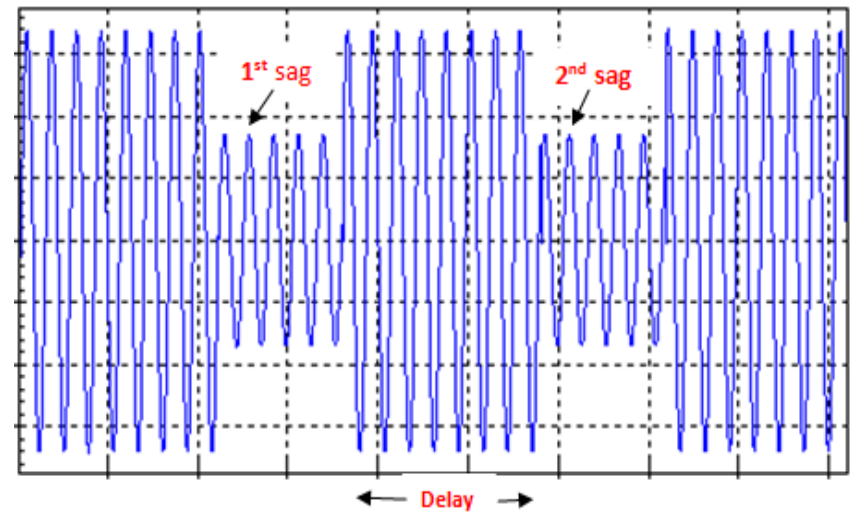

(b) Waveform repetitive voltage sag event

Fig. 1 The characteristics of voltage sag generator outputs.

Magnitude and duration of voltage sags are main characteristics of the voltage sags which are very influenced on equipments performance [1]. These characteristics become consideration in this study for investigating performance of the contactor and induction motor. Other characteristics are point on wave of sag initiation and repetitive of voltage sags (double sags). All characteristics can appear when a power system short circuit faults experience.

\section{METHODS AND EQUIPMENT USED}

\section{A. Testing Facility}

A 9 kVA Programmable source "Tэseq" is equipment which is capable of producing any arbitrary waveform and event at the power rating and 0-300 V RMS amplitude/phase. Personal computer has been used for adjusting to produce sag characteristics desired. The equipment is shown in Fig. 2.

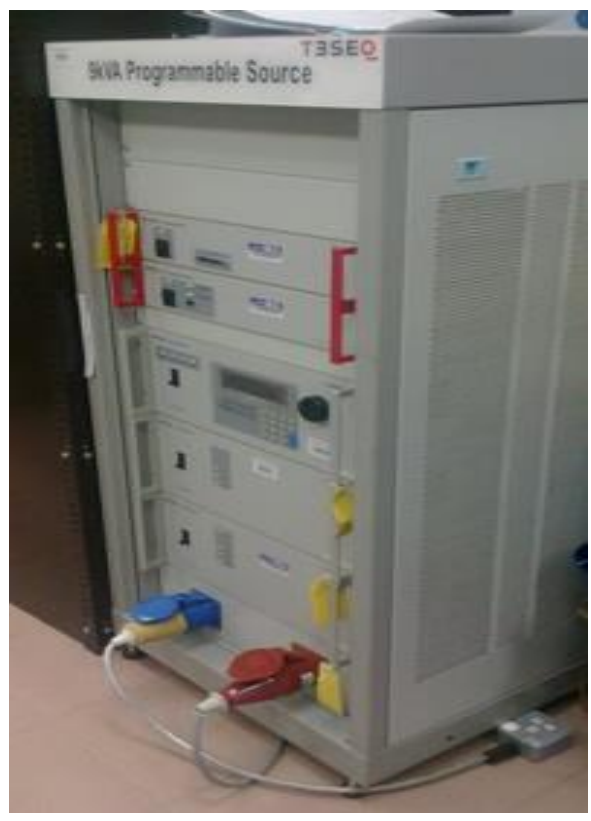

Fig. 2 A Programmable source used for generating voltage sags

\section{B. Contactor Testing}

A small contactor $240 \mathrm{~V}$, continuous rating of $20 \mathrm{~A}$ and frequency $50 \mathrm{~Hz}$ was used to investigate effect of voltage sags. Sag characteristics are applied in various depth, duration, and point on wave of sag initiation where induction motor was used as load. Procedure of testing of the contactor as follows:

1. Main electrical contact is supplied by applying nominal voltage, 240 Volt.

2. Duration starting of $10 \mathrm{~ms}$ to $200 \mathrm{~ms}$ in step 10 milliseconds.

3. The sag magnitude was set to depth varying from $70 \%$ to $0 \%$ with a step of $2.5 \%$.

4. Point on wave was adjusted for $0^{\circ}, 30^{\circ}, 45^{\circ}, 60^{\circ}, 90^{\circ}$.

5 . If the voltage sags of certain magnitude, duration and point on wave causes the contactor to trip was assumed to be sensitive to this type of sags then are recorded.

6. For to find sensitivity curve of contactor each characteristic was reproduced repeatedly two to three times to avoid errors caused by in contactor performance.

7. Especially for repetitive of voltage sags event, the sag characteristics used are certainty.

\section{Induction Motor Testing}

A small three phase induction motor $0.37 \mathrm{~kW}, 1400 \mathrm{rpm}$ and 0.8 power factor was used for the testing. The motor was supplied by balance voltage sags with various sag characteristics. Sag magnitude was adjusted beginning from $90 \%$ to $0 \%$ of the nominal voltage in step $10 \%$ increments with different sag duration of 50,100 and 200 milliseconds. 
To investigate influence of sag duration on the current, testing was carried out for duration of $25,50,100,150,200, \ldots, 500$ milliseconds. The values of current peaks are designated in p.u which is ratio between current peak due to voltage sag and normal conditions.

\section{RESULTS AND DISCUSSION}

\section{A. Contactor Performance Due to Magnitude and Duration of Voltage Sags.}

The magnitude and duration of voltage sags are main sag characteristics very important that determined performance of contactors. There are several studies consider voltage sag magnitude and duration only as parameters, which are through experimental and develops model using digital simulation software $[5,6]$. The contactors trip is great influenced by sag magnitude and sag duration of voltage sags.

To investigate influence of sag magnitude and sag duration on the performance of the contactor can be observed throughout Fig. 3 and Fig. 4. From Fig. 3(a) and (b) which are the contactor was subjected to voltage sag with different sag magnitude and in similar sag duration. When the contactor was subjected to voltage of 55\% sag depth, the contactor did not trip (in Fig. 3(a)), and when sag magnitude increases until depth of $45 \%$, the contactor trips (in Fig. (3b)). The contactor trip is shown by current waveform through coil contactor is zero, therefore there is no energy supplied to load (induction motor).

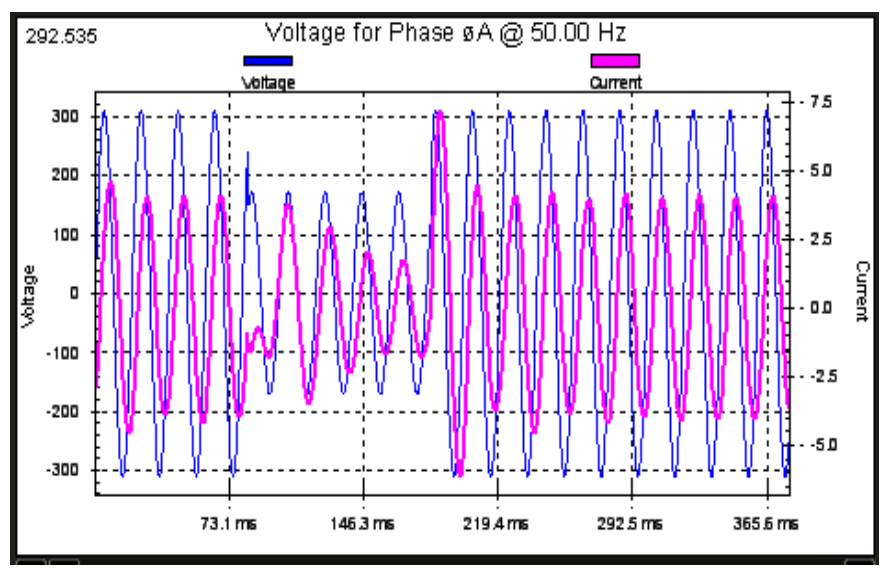

(a) Voltage sag (55\% depth, $100 \mathrm{~ms}$ in duration), the contactor did not trip

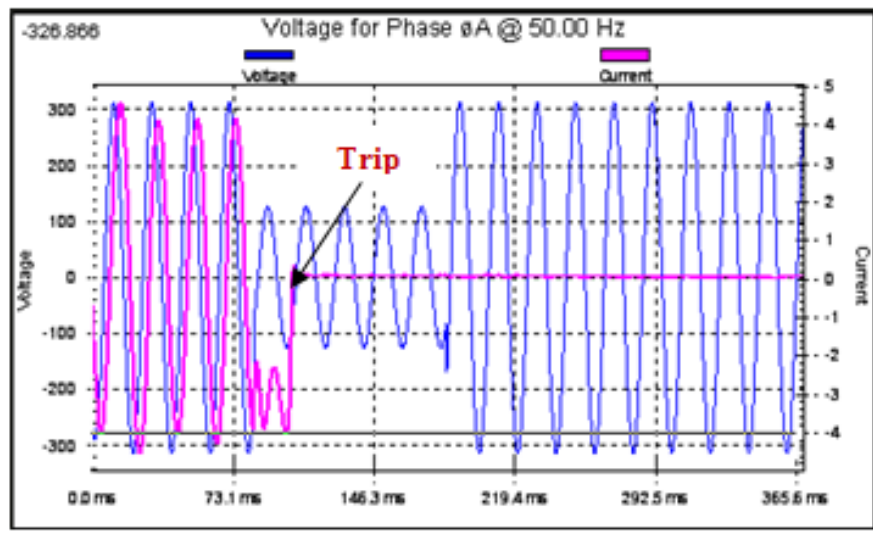

(b) Voltage sag (45\% depth, $100 \mathrm{~ms}$ in duration), the contactor trip

Fig. 3 Performance of voltage and current waveform for the contactor was subjected to voltage sag $100 \mathrm{~ms}$ in duration.

In similar way in Fig. 4(a) and (b) shown different contactor performance for different sag duration and similar sag magnitude. In Fig. 4(a) the contactor did not trip in $10 \mathrm{~ms}$ and if sag duration increases to $20 \mathrm{~ms}$, the contactor becomes trip (Fig. 4(a)). From these performances can be explained that the contactor trip or drop out is greatly influenced by two parameters i.e., sag magnitude and sag duration.

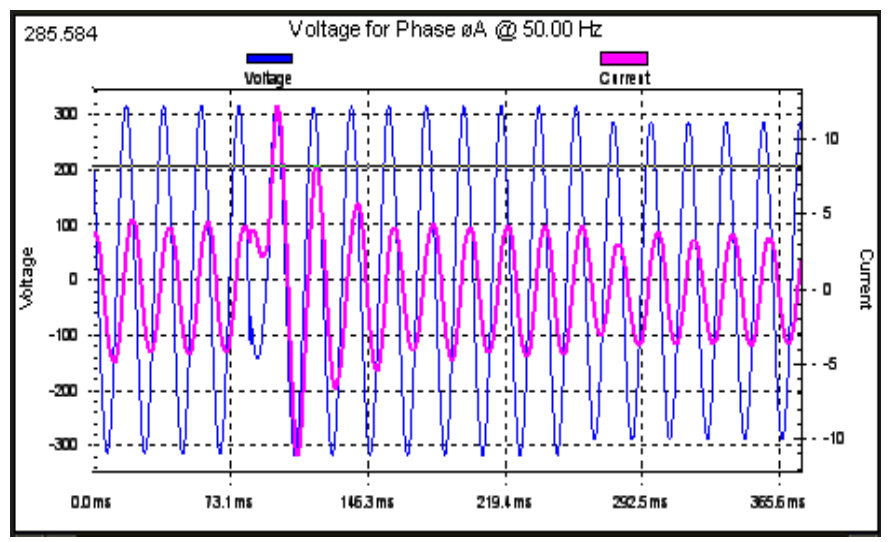

(a) Voltage sag (45\% depth, $10 \mathrm{~ms}$ in duration), the contactor trip

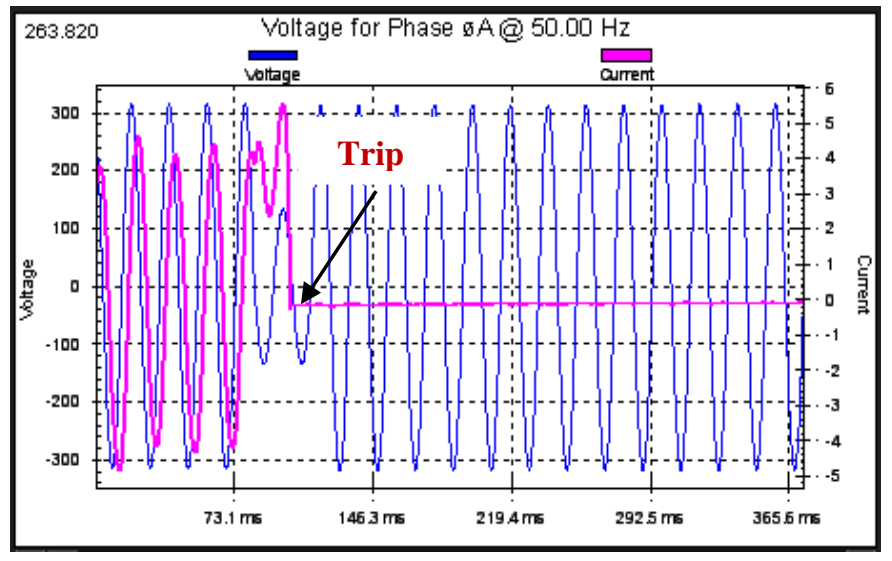

(b) Voltage sag (45\% depth, $20 \mathrm{~ms}$ in duration), the contactor trip 
Fig. 4 Performance of voltage and current waveform for the contactor was subjected to voltage sag of $45 \%$.

\section{B. Performance of the Contactor Due to Point on Wave of Sag Initiation.}

POW of voltage sag initiation is one of other factors that influenced on performance of the contactors. This is indicated by sensitivity curve such as in Fig. 5. This figure shows sensitivity curves of the contactors for different POW of voltage sag initiation $\left(0^{\circ}, 30^{\circ}, 45^{\circ}, 60^{\circ}\right.$ and $\left.90^{\circ}\right)$. From the figure clearly that sensitivity of the contactor to voltage sag generally is different and it is very influenced by the POW of sag initiation. As illustration, the contactor is more sensitive to voltage sag magnitude at POW of $60^{\circ}$ with the sag magnitude threshold value of $40 \%$. Sensitivity to sag duration almost similar to all POWs which the contactor starting to trip at 20 ms. Especially intresting is the sensitivity of the contactor is not vertical line to sag duration for POW of less than $90^{\circ}$ and it generally less sensitive to longer sag duration.

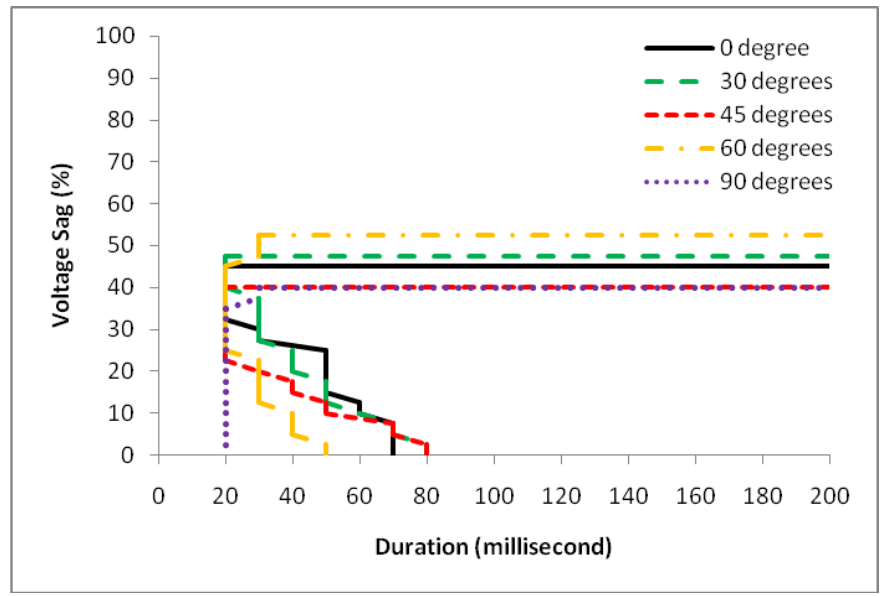

Fig. 5 Sensitivity of contactor in various POW

\section{Performance of Contactor Due to Repetitive of Voltage Sags.}

Fig. 6 shows two different conditions, where the contactor was subjected to repetitive voltage sags. In Fig. 6(a) shows the contactor was supplied by repetitive event with sag magnitude of $60 \%$ and $50 \mathrm{~ms}$ in duration for each event. It did not trip because voltage sag applied on the contactor still lower than value threshold that caused the contactor to trip. Then testing was continued by increasing sag magnitude and sag duration. The sag magnitude selected is the critical value that cause the contactor trip i.e., $45 \%$ depth. Performance of the contactor is shown in Fig. 6(b) which is the contactor trip for second sag but in first sag it did not trip. This indicate that repetitive of voltage sag can influence on contactor performance that result in the contactor trip. The contactor trip after around half cycles sag occurs.

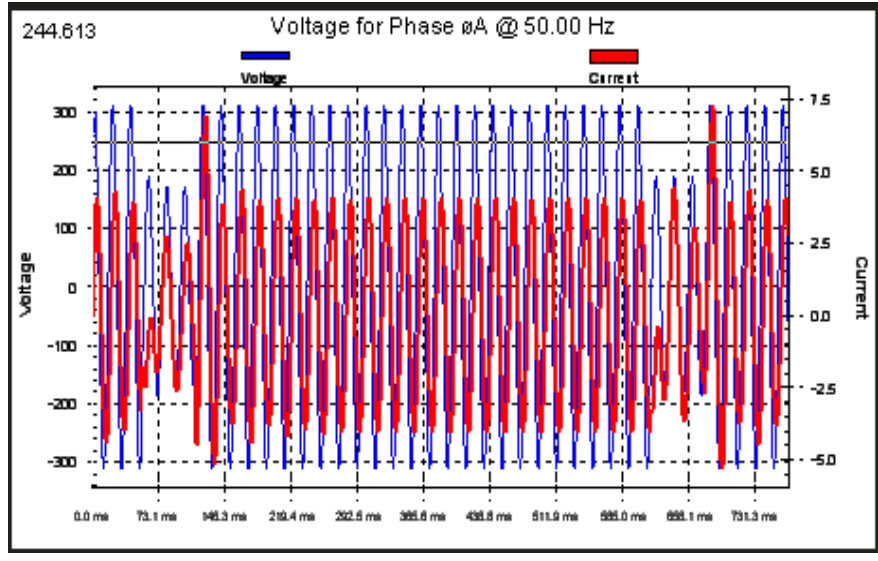

(a) Voltage sag (60\% depth, 50 ms duration), the contactor did not trip

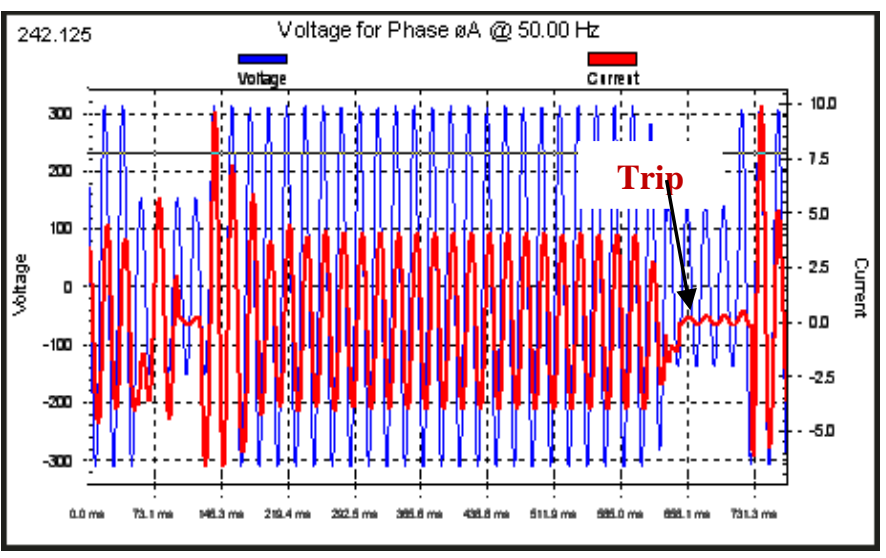

(b) Voltage sag (45\% depth, $80 \mathrm{~ms}$ duration), the contactor trip.

Fig. 6 Wave form of voltage and current on the contactor due to repetitive of voltage sags event.

\section{Performance of Induction Motor Due to Sag Magnitude and Sag Duration.}

Influences of sag magnitude and sag duration on induction motor are shown in Fig. 7 and Fig. 8. The current peak is current maximum occurred due to voltage sags. Commonly it happened after the voltage sag is over (recovery voltage). In Fig. 7 the motor was subjected to voltage sags from $90 \%$ to $0 \%$ in different sag duration. The current peaks are higher for deeper sag, even for interruption the current peaks can reach more than 4 per unit. Eventhough the curve shows tend linear, the current increasing is higher when the voltage sag occurs for sag magnitude of 30 up to 50\%. For voltage sag magnitude of $90 \%$ to $40 \%$, the current peaks produced are almost similar.

From Fig. 8, it can be seen that the current peak caused by sag magnitude of $80 \%$ and $50 \%$ in is not influence significantly for sag duration $25,50,75,100,150,200, \ldots$, to $500 \mathrm{~ms}$ and the curves tend linear. This is according to simulation result from previous study that state the current peak and torque peak produced in different sag duration is not 
significant and thy always occur at the beginning of voltage sag [7].

The current peak caused by sag magnitude of $20 \%$ tend is not linear and the current tend increases then approximately linear. In interruption event, the current increase sharply and then decrease gradually. The current increasing too large occurs in shorter sag duration below 100 milliseconds. The same result also was indicated in [8] by simulation which the induction motor was subjected to sag magnitude of $10 \%$. The current peak is higher slightly for duration less than 200 millisecond. Therefore sag duration has little influence on the current peaks.

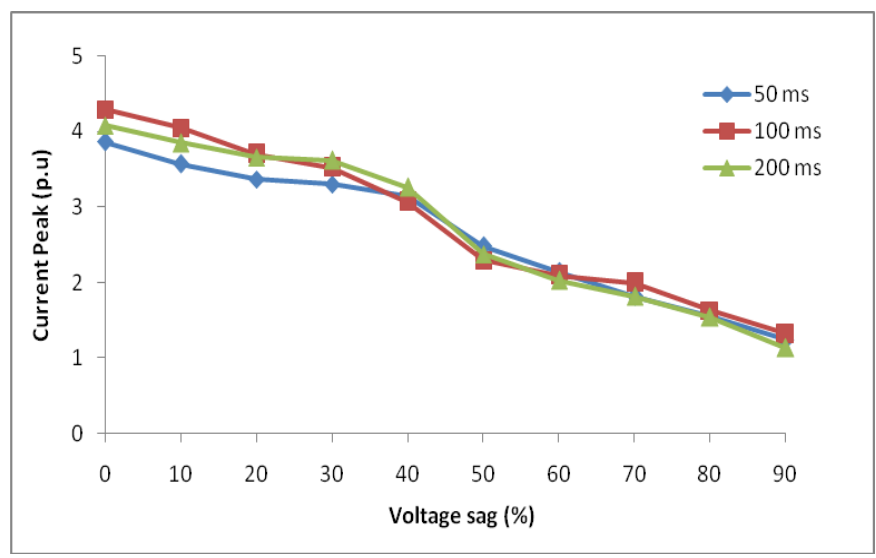

Fig. 7 The current peak Vs sag magnitude in different sag duration

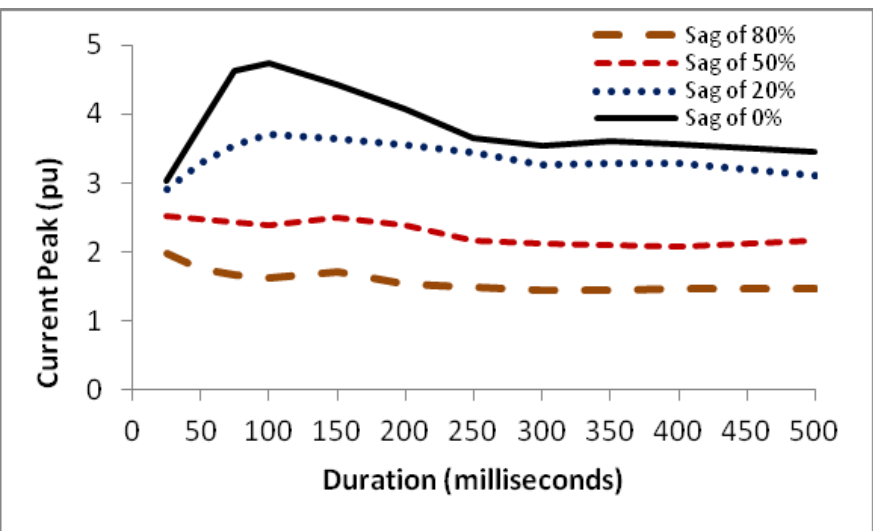

Fig. 8 The Current Peak Vs sag duration

\section{E. Performance of Induction Motor Due to Repetitive of Voltage Sags.}

The purpose this testing is to investigate motor performance on the current peak in second sag caused by first sag duration. Several different sag durations are carried out in first sag duration. The value of sag magnitude is similar to $50 \%$ depth for each of voltage sags. The sag durations in second sag is remain in $100 \mathrm{~ms}$ and the results are shown in Fig. 9

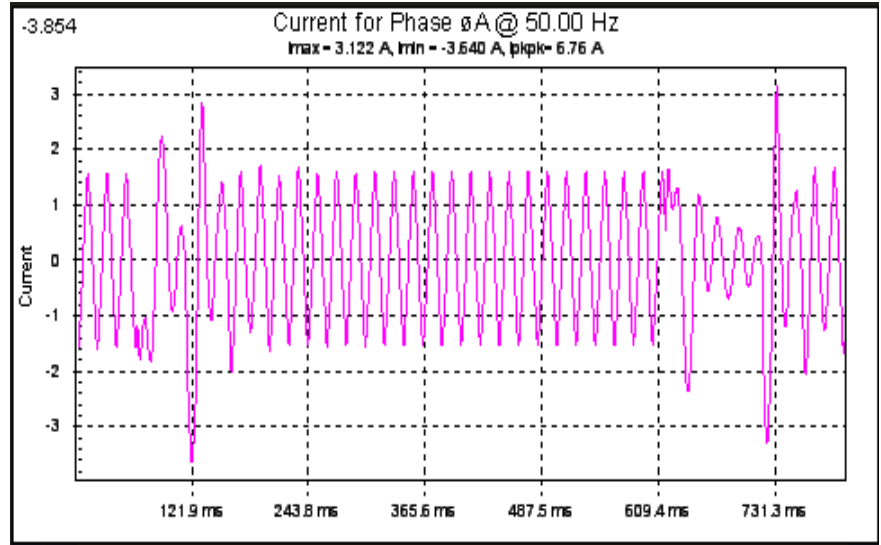

(a) For fist sag duration of $50 \mathrm{~ms}$

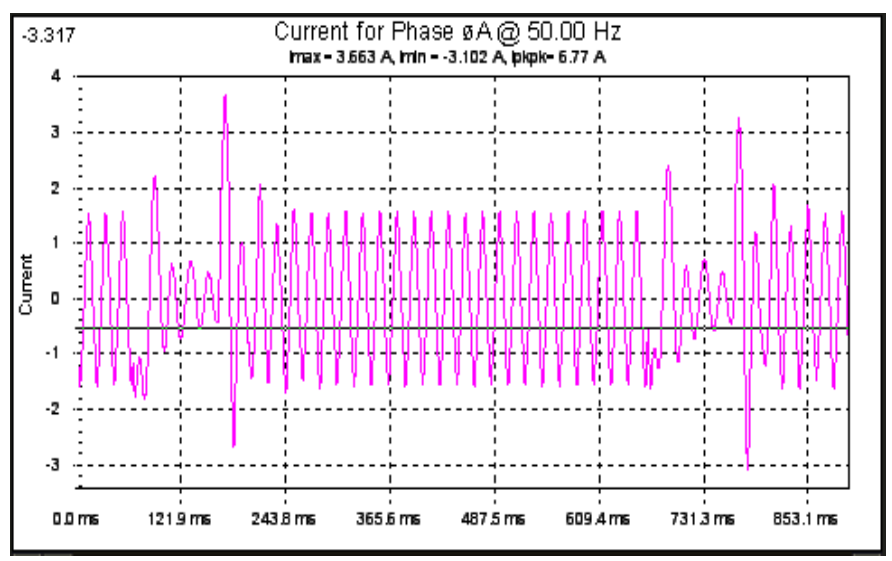

(b) For first sag duration of $100 \mathrm{~ms}$

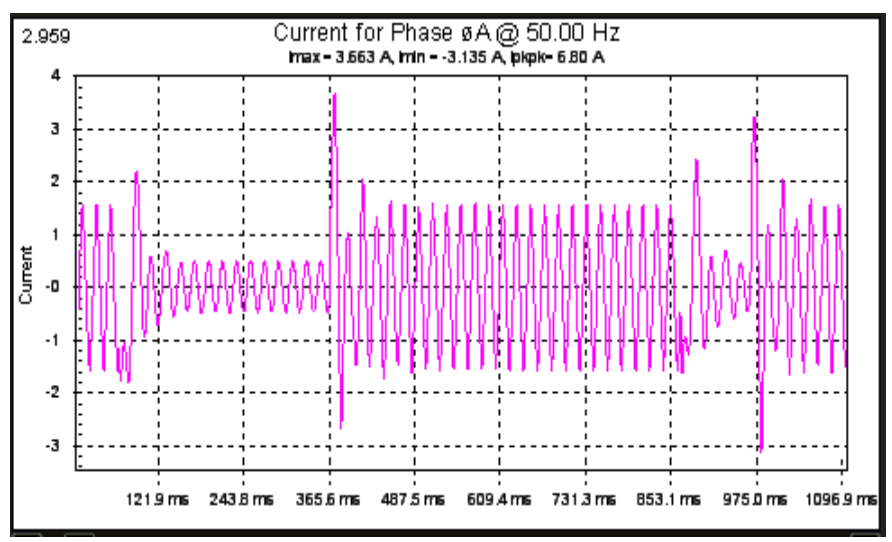

(c) For first sag duration of $300 \mathrm{~ms}$

Fig. 9 Current waveform of the motor caused by repetitive of voltage sags in different first sag duration.

. The current peaks are shown only in phase-a because the current peak is higher than two other phases. Based on result obtained can be observed that there is no difference significantly occurred on the current peak in second sag caused by different duration of the first voltage sag. The current peaks resulted in second sag is almost similar to all sag duration. 


\section{CONCLUSION}

Voltage sag may occur at the supply terminal of the industrial caused by short circuit fault in utility transmission or distribution that it supplies. Various characteristics of the voltage sag were applied on the equipments to investigate they performance. By doing varies sag magnitude and sag duration, from test results show that magnitude and duration of the voltage sags have great influence on performance contactor. It starts to trip at $20 \mathrm{~ms}$ sag duration. The value of sag magnitude threshold is depending on point on wave of sag initiation. The minimum sag magnitude threshold when the contactor was subjected to voltage sag with POW of 60 degrees, it trips at sag magnitude of $60 \%$. Repetitive of voltage sag event can become the contactor more sensitive.

The result also is shown on induction motor where sag magnitude has great influence on the current peaks, but sag duration is not significant. Influence sag duration on the current peak due to interruption occurs in short time only. Occurrence of the second voltage sag after the first sag produces the same current peaks.

\section{REFERENCES}

[1] M. H. J. Bollen,'Understanding of power quality problems: Voltage sag and interruptions", IEEE Press Series on Power Engineering, 2000.

[2] Angel Felce, Guilermo Matas, Ysmael Da Silva,"Voltage sag analysis and solution for an industrial plant with embedded induction motor". Industry Applications Conference, 2004.39th IAS Annual Meeting. Conference Record of the 2004 IEEE. Industry Applications Conference, 2004. 39 $9^{\text {th }}$ IAS Annual Meeting._Volume: 4, pp. 25732578 .

[3] D. H. Tourn, J. C. Gomez,.“ Effect of system recovery on induction motor protection using HBC fuses, following a short circuit fault, Industry Applications Conference, 2001. Thirty- Sixth IAS Annual Meeting. Conference Record of The 2001 IEEE Volume:3.

[4] C. P. Gupta. and J. V. Milavonic., Probabilistic assessment of equipment trips due to voltage sags, IEEE Trans. Power Delivery, 21(2), 711-718, (2008).

[5] Karady George, G., Saurabh Saksen, Baozhuang Shi, Nilanjan Senroy. Effects of Voltage Sags on Loads in a Distribution. Final Project Report, Power system engineering research center, October, 2005.

[6] Hasmani Mohamad and Khalid Mohd. Nor,"Evaluation on sensitivity of ac contactor during voltage sag' TENCON 2004, 2004 IEEE Region 10 Conference Volume C.

[7] L. Guash,, F. Corcoles and J. Pedra."Effect of symmetrical and unsymmetrical voltage sags on Induction Machines,"IEEE Trans. On Power Delivery, vol. 19.,N0. 2, April, 2004.

[8] J. Pedra, L. Sainz and F. Corcoles, Effects of symmetrical voltage sags on squirrel cage Induction Motors, Electrical Power System Research, (2007).M. Young, The Techincal Writers Handbook. Mill Valley, CA: University Science, 1989.
Surya Hardi received the Bachelor and M.Sc degrees in Electrical Engineering from University of North Sumatra (USU) and from Institute of Bandung Technology (ITB), Indonesia in 1985 and 1992, respectively. $\mathrm{He}$ is currently pursuing $\mathrm{Ph} . \mathrm{D}$ degree at UniMAP Malaysia. Currently, he is a senior lecturer at University of North Sumatra, Indonesia. His research interest includes, power quality and power system grounding, and electrical energy forecasting.

Muhd Hafizi Idris was born in Alor Star, Malaysia in 1983. He received the B.Eng degree in Electrical and Electronic Eng. from University Kebangsaan Malaysia (UKM) in 2006 and M.Eng Electrical Power from University Technology Malaysia (UTM) in 2011. His fields of interest include power system protection, stability, reliability and power quality. Currently he is working as a lecturer in Universiti Malaysia Perlis.

Muzamir Isa was born in Padang Besar, Perlis, Malaysia in 1979. $\mathrm{He}$ received the B.Sc. degree from the University Technology of Malaysia (UTM), Skudai, Johor, Malaysia in 2001, the M.Sc. degree from the Tun Hussein Onn University of Technology, Batu Pahat, Johor, Malaysia in 2004. In January, 2013, he received his Ph.D degree from Department of Electrical Engineering, Aalto University, Finland. His research interests are partial discharge measurement, detection and location technique, and power system transient studies including EMTP simulation and power Quality. Currently, he is working as a senior lecturer in Universiti Malaysia Perlis

Rohana Ismail received the Bachelor degree in Electrical Engineering from university of Muhamadyah Sumatera Utara in 2000 and Master degree in Industrial Engineering from University of North Sumatra (USU), Indonesia in 2008. Her research interest includes; Electrical power management and power quality. 